Volume 14 - Número 2 - ago/dez de 2019

\title{
RELAÇÕES TEXTO ESCRITO-IMAGÉTICO EM VERBETES ILUSTRADOS DE UM DICIONÁRIO BILÍNGUE DE INGLÊS
}

\section{RELATIONS BETWEEN WRITTEN AND IMAGETIC TEXTS IN ILLUSTRATED ENTRIES OF A BILINGUAL ENGLISH DICTIONARY}

\author{
Aryanne Christine Oliveira Moreira ${ }^{1}$ \\ Lorena Américo Ribeiro ${ }^{2}$ \\ Antonia Dilamar Araújo ${ }^{3}$
}

\begin{abstract}
RESUMO: Neste artigo, investigamos relações entre textos escrito e imagético em verbetes ilustrados de um dicionário bilíngue, o Longman Dicionário Escolar para Estudantes Brasileiros Inglês-Português / PortuguêsInglês (2009). Tomamos como base para nossas análises o modelo teórico de Martinec e Salway (2005) sobre as diferentes possibilidades de relações de status e lógico-semânticas que podem ocorrer entre textos escrito e imagético. Concluímos, a partir da análise de quatro verbetes do dicionário, que os textos escrito e imagético podem se relacionar de forma igual, complementando-se ou não, ou desigual, com o texto escrito subordinado ao texto imagético. Além disso, os textos escrito e o imagético podem apresentar-se em um mesmo de nível de generalidade, ou o texto escrito pode ser mais geral e o imagético uma representação específica da parte escrita. Finalmente, o texto imagético pode acrescentar informações que não são fornecidas pelo texto escrito, ou viceversa.
\end{abstract}

PALAVRAS-CHAVE: Escrita. Imagem. Dicionário bilíngue.

ABSTRACT: In this paper, we investigate imagetic and written texts relations in illustrated entries of a bilingual dictionary, the Longman Dicionário Escolar para Estudantes Brasileiros Inglês-Português / Português-Inglês (2009). As a reference for our analyses, we considered Martinec and Salway's (2005) theoretical framework about the different possibilities of status and logic-semantics relations that may occur between written text and imagetic one. We concluded, based on the analysis of four entries in the dictionary, that the written text and the imagetic may relate each other on an equal status, complementing each other or not, or on an unequal status, with the written text subordinated to the imagetic one. Besides that, the written text and the imagetic one may be in the same level of generality, or the written text may be more general and the imagetic text a specific representation of a portion of written language. Finally, the imagetic text may add information that is not conveyed by the written text, or vice versa.

KEYWORDS: Writing. Image. Bilingual dictionary.

\section{Introdução}

Os dicionários, sejam eles de língua materna ou de língua estrangeira, vêm evoluindo com o passar dos anos. Essa evolução pode ser observada tanto em seu suporte (impresso ou eletrônico), quanto em sua estrutura composicional. Se considerarmos, por exemplo, os dicionários impressos confeccionados há 20 ou 30 anos e os compararmos com os dicionários impressos atuais, certamente identificaremos uma sorte de diferenças não somente lexicais, mas também estruturais e composicionais.

Considerando os dicionários de língua estrangeira (no caso deste estudo, dicionários de inglês) voltados para aprendizes, é possível perceber o quanto essas obras vêm explorando, cada vez mais, o visual. No que tange à estrutura dessas obras (bilíngues ou monolíngues),

\footnotetext{
1 Mestranda do Programa de Pós-Graduação em Linguística Aplicada da Universidade Estadual do Ceará (UECE). Fortaleza, Ceará, Brasil. E-mail: aryanne.moreira@aluno.uece.br.

${ }^{2}$ Doutoranda do Programa de Pós-Graduação em Linguística Aplicada da Universidade Estadual do Ceará (UECE). Fortaleza, Ceará, Brasil. E-mail: lorafechine@gmail.com.

${ }^{3}$ Professora Doutora e Titular da Universidade Estadual do Ceará. Professora do Programa de Pós-Graduação em Linguística Aplicada (UECE) e coordenadora do projeto Multimodalidade e Letramento Visual: estudos de relações intersemióticas em textos multimodais e práticas de letramentos em contextos educacionais (MULTILETRA). E-mail: dilamar.araujo@uece.br
} 
Volume 14 - Número 2 - ago/dez de 2019

observamos que os elementos visuais podem ser trazidos tanto na megaestrutura ${ }^{4}$, quanto na

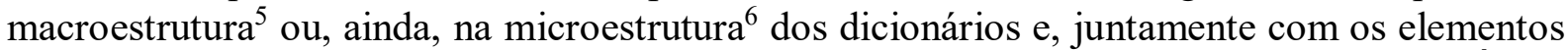
escritos, formam uma unidade cujo intuito é facilitar a compreensão de sentidos. É em observância a essas questões que tecemos os objetivos deste estudo. Dessa forma, o presente trabalho propõe analisar as relações entre texto escrito e texto imagético/visual presentes na microestrutura de verbetes ilustrados de um dicionário bilíngue para aprendizes de inglês.

Para realização das análises, tomamos como base o modelo teórico de Martinec e Salway (2005). No entanto, para compor nosso referencial teórico, consideramos, ainda, outras leituras, com as quais dialoga esse estudo. Dentre elas, podemos citar Duran (2004), Lew (2010), van Leeuwen (2005), Kress e van Leeuwen (2006), Jewitt e Oyama, (2008), Jewitt (2014), Barthes (1977) e Halliday e Matthiessen (2014).

Para a estruturação deste artigo, primeiramente abordamos sobre o dicionário bilíngue como uma obra multimodal e, em seguida, tratamos sobre as relações escrita-imagem, particularmente sobre o modelo proposto por Martinec e Salway (2005), base para nossas análises. Após essas questões teóricas, trazemos a seção metodológica, em que apresentamos uma breve descrição do material de análise, ou seja, o dicionário bilíngue escolhido para exame, e explicitamos os critérios para seleção dos verbetes da obra que serão analisados, bem como os procedimentos que serão adotados para a análise. Por fim, apresentamos nossas conclusões acerca do estudo.

\section{Dicionário bilíngue como obra multimodal}

Não há dúvidas que o dicionário é um importante material didático no processo de ensino e aprendizagem, seja da língua materna (LM), seja de uma língua estrangeira (LE). No Brasil, no que se refere ao ensino de Língua Portuguesa, dicionários de língua materna são adotados como materiais didáticos (BRASIL, 2012). Já com relação ao ensino de Língua Inglesa, a Base Nacional Comum Curricular (BNCC) aborda que, no $6^{\circ}$ ano do ensino fundamental - anos finais, "conhecer a organização de um dicionário bilíngue (impresso e/ou on-line) para construir repertório lexical" (BRASIL, 2017, p. 249) é uma das habilidades que deve ser desenvolvida. Dessa forma, compreendemos que o estímulo ao uso do dicionário bilíngue nas aulas de Inglês cabe ao professor. Cabe a ele, ainda, a responsabilidade da escolha de um bom dicionário, o qual atenda às necessidades de aprendizagem de seus estudantes, conforme afirmam Höfling, Silva e Tosqui (2004).

O uso do dicionário bilíngue por estudantes de uma LE, contudo, nem sempre foi visto positivamente. Bastante valorizado no século XIX, quando sua função era prioritariamente estabelecer equivalências entre duas línguas, o estímulo ao uso dessa obra lexicográfica começou a ser diminuído ou, até mesmo, desaconselhado, quando novos métodos de ensino de LE, tais como o Método Direto, o Audiolingual e o Comunicativo, foram surgindo. Uma vez que esses métodos não estimulavam traduções nem o uso da língua materna durante o processo de aprendizagem da língua estrangeira, por muitas vezes, os dicionários indicados nesse período foram os monolíngues de LE (DURAN, 2004). Contudo, com o surgimento da abordagem lexical, que considerava o uso da LM como base para o aprendizado da LE, já que previa atividades que consideravam comparações entre ambas as línguas, o uso do dicionário bilíngue voltou a ser estimulado (DURAN, 2004).

Usar obras lexicográficas bilíngues, no entanto, passou a ir além da simples consulta a equivalentes, já que se estimulava "o uso criativo do dicionário em sala de aula." (DURAN, 2004, p. 28). O trabalho de Barcelos (2014), por exemplo, aborda essa questão, já que seu

\footnotetext{
${ }^{4}$ Estrutura global do dicionário. Compreende as informações fornecidas pela obra de capa a capa.

${ }^{5}$ Conjunto de entradas do dicionário.

${ }^{6}$ Conjunto de informações descritivas da entrada.
} 
Volume 14 - Número 2 - ago/dez de 2019

estudo envolveu a elaboração de um glossário próprio para alunos em nível A1 (iniciante) de um curso de Inglês. Esse glossário foi produzido pelos próprios alunos, após realizarem pesquisas em diferentes dicionários bilíngues de Inglês disponibilizados em sala de aula. A finalidade era que o glossário fosse usado em atividades futuras.

É importante considerar que os dicionários, especialmente os escolares, vêm, cada vez mais, apresentando configurações que visam a promover melhor compreensão ao usuário. Com os dicionários bilíngues, isso não é diferente. Dentre essas configurações, Duran (2004) chama a atenção para a presença de elementos lexicográficos mais adequados para efetivar a aquisição do léxico, tais como definições, exemplos de uso, equivalentes, sinônimos, ilustrações etc. Já o estudo de Lew (2010) contempla, inclusive, o termo Lexicografia Multimodal, o qual considera que a construção de significados no dicionário realiza-se não somente pelo modo semiótico verbal, mas também pelo modo visual, através de fotografias, ilustrações, desenhos, figuras, gráficos, cores, layout e outros.

Conforme observamos em Lew (2010) e tendo em mente a Teoria da Multimodalidade (VAN LEEUWEN, 2005; KRESS; VAN LEEUWEN, 2006; JEWITT; OYAMA, 2008; JEWITT, 2014), compreendemos os dicionários como multimodais. Considerando, ainda, a microestrutura dos verbetes, entendemos que os modos semióticos que os compõem (verbais ou não verbais) orquestram-se entre si para construir significados. Dessa forma, consideramos os verbetes como textos multimodais e entendemos, além disso, o dicionário como uma obra lexicográfica não apenas de consulta, mas como um livro que deve ser lido e compreendido, conforme defendem Lima, Araújo e Pontes (2016).

\section{Relação escrita-imagem}

É possível considerar que analisar composições textuais que integram escrita e imagem torna-se mais complicado que analisar um texto unicamente escrito, por exemplo, visto que análises de textos multimodais exigem uma carga analítica maior por parte de quem os analisa (BATEMAN, 2014). Nesses textos, o leitor se depara não apenas com a necessidade de observar, separadamente, cada modo semiótico integrante da composição, mas também de compreender a relevância de analisar o todo. Dessa forma, compreendemos que, para a análise de um texto multimodal, necessitamos observar tanto o sentido que cada modo apresenta, individualmente, quanto o sentido construído pela integração desses modos, ou seja, o sentido do todo. Para este estudo, descreveremos brevemente duas importantes teorias no que refere às relações escrita-imagem: a teoria de Barthes (1977), uma das pioneiras, e a teoria de Martinec e Salway (2005), na qual nos embasamos para as análises do corpus deste trabalho.

No que tange à relação entre texto escrito e texto imagético, de acordo com o que depreendemos de Barthes (1977), é possível compreender três funções: a de ancoragem, a ilustrativa e a de relay. $\mathrm{Na}$ função de ancoragem, o texto escrito dá suporte para o todo do texto imagético (ou para partes deste), com o intuito de elucidação ou controle, uma vez que indica informações específicas a serem observadas na imagem. Logo, o texto escrito ancora as informações do texto imagético, mantendo uma relação de dependência para com esta. Quanto à função ilustrativa, a imagem dá suporte à escrita com a finalidade de elucidá-la ao leitor. Sendo assim, a imagem é dependente do texto escrito, visto que o ilustra. Já a função de relay é observada quando escrita e imagem se complementam entre si, ou seja, ambos podem ser, em relação de igualdade, componentes de uma mesma mensagem. Dessa forma, texto escrito e imagem contribuem para a construção do sentido do todo, como se percebe, por exemplo, em histórias em quadrinhos.

Quanto ao modelo de Martinec e Salway (2005), este traz uma releitura das ideias de Barthes (1977) e de Halliday (HALLIDAY; MATTHIESSEN, 2014). É um modelo 
Volume 14 - Número 2 - ago/dez de 2019

complexo, já que é bastante abrangente no que se refere às relações entre escrita e imagem. Com base nas ideias de ancoragem, ilustração e relay, observadas no estudo de Barthes (1977), Martinec e Salway (2005) propõem que imagem e texto escrito mantêm relações de status, as quais podem ser iguais ou desiguais.

No status igual, a totalidade da imagem está relacionada ao todo do texto escrito. Ambos os modos semióticos (escrita e imagem) podem, então, manter uma relação de independência ou de complementaridade. Quando o texto escrito e a imagem são observados sem que um necessariamente venha a modificar o outro, temos uma relação de independência. Já quando ambos se organizam de forma que um modifica o outro (mas atuando em correlação, não em subordinação), temos uma relação de complementaridade.

Quanto ao status desigual, é possível observar, nesse tipo de relação escrita-imagem, uma certa dependência entre os elementos componentes de ambos os modos, sendo evidente que um (modificador) modifica o outro (modificado). Dessa forma, pode ocorrer uma relação de subordinação tanto da imagem para com o texto escrito, quanto do texto escrito para com a imagem.

Já conforme o depreendido de Halliday (HALLIDAY; MATTHIESSEN, 2014), Martinec e Salway (2005) compreendem que imagem e escrita mantêm, ainda, relações lógico-semânticas podem ser tanto de expansão, quanto de projeção. Nesse tipo de relação, a escrita e a imagem são vistas como orações e o composto escrita-imagem é compreendido como uma oração complexa.

A relação de expansão pode subdividir-se em elaboração, em extensão, ou em ampliação, sendo que a relação de elaboração pode se subdividir, ainda, em exposição e em exemplificação. A relação de exposição ocorre quando o texto escrito e a imagem estão no mesmo nível de generalidade. Já a exemplificação é observada quando ambos apresentam níveis de generalidade diferentes. Na extensão, imagem e texto escrito podem vir a adicionar novas informações um ao outro, ou seja, a imagem pode acrescentar novas informações à escrita, ou vice-versa. Já a relação de ampliação é observada quando o texto escrito qualifica a imagem, ou o contrário. Essa qualificação pode estar relacionada a questões de circunstância (tempo, espaço ou finalidade), ou, ainda, de consequência.

No que concerne à relação de projeção, na qual um modo apresenta eventos que já foram apresentados por outro modo, esta subdivide-se em: locução, quando é apresentada uma projeção do texto escrito, geralmente por um processo verbal; e ideia, em que se apresenta a projeção de sentido de um pensamento, na maior parte das vezes, por um processo mental.

Um esquema do modelo proposto por Martinec e Salway (2005) para análise da relação entre escrita e imagem dos verbetes selecionados pode ser observado no Quadro 1.

\section{Quadro 1 - Relações entre escrita e imagem conforme Martinec e Salway (2005)}

\begin{tabular}{|c|c|c|c|c|}
\hline \multirow{4}{*}{$\begin{array}{c}\text { Relações } \\
\text { de } \\
\text { status }\end{array}$} & \multirow{2}{*}{ Igual } & \multicolumn{2}{|c|}{ Imagem e texto escrito independentes } & \\
\hline & & \multicolumn{2}{|c|}{ Imagem e texto escrito complementares } & \\
\hline & \multirow{2}{*}{ Desigual } & \multicolumn{2}{|c|}{ Imagem subordinada ao texto escrito } & \\
\hline & & \multicolumn{2}{|c|}{ Texto escrito subordinado à imagem } & \\
\hline \multirow{8}{*}{$\begin{array}{l}\text { Relações } \\
\text { lógico- } \\
\text { semânticas }\end{array}$} & \multirow{6}{*}{ Expansão } & \multirow[b]{2}{*}{ Elaboração } & Exposição & \\
\hline & & & Exemplificação & Texto escrito mais geral \\
\hline & & Extensão & & \\
\hline & & \multirow{3}{*}{ Ampliação } & Tempo & \\
\hline & & & Espaço & \\
\hline & & & Finalidade & \\
\hline & \multirow{2}{*}{ Projeção } & Locução & & \\
\hline & & Ideia & & \\
\hline
\end{tabular}

Fonte: Adaptado e traduzido de Martinec e Salway (2005, p. 360). 
Volume 14 - Número 2 - ago/dez de 2019

\section{Metodologia}

\subsection{Material de análise}

Para este trabalho, selecionamos o dicionário bilíngue Longman Dicionário Escolar para Estudantes Brasileiros Inglês-Português / Português-Inglês, segunda edição, de 2009, visto que, conforme o trabalho de Humblé (2006), este é um dicionário bilíngue de "ótimo nível" (HUMBLÉ, 2006, p. 271) para estudantes brasileiros de inglês.

Com base nos critérios de funcionalidade, direcionalidade e reciprocidade, descritos por Duran $(2004)^{7}$, compreendemos que a obra lexicográfica selecionada é bidirecional, pois apresenta tanto as funções de decodificação, quanto as de codificação. $O$ dicionário é, ainda, não-recíproco, visto que é voltado explicitamente para estudantes brasileiros, de acordo com o descrito pela própria obra (LONGMAN, 2009). Quanto à sua composição, apresenta 127.000 vocábulos, exemplos e traduções e traz, ainda, 250 quadros explicativos e 1.000 notas sobre palavras-chave ou sobre problemas de tradução (LONGMAN, 2009).

Ao analisarmos a obra, contabilizamos um total de 205 verbetes ilustrados, todos com imagens fotográficas. Desses, 136 compõem a direção inglês/português, e os 69 restantes, a direção português/inglês. Embora o dicionário apresente, ainda, informações importantes em suas páginas iniciais (chaves de pronúncia e abreviaturas e um guia de uso) e, ainda, apresente um rico material interposto (caderno de atividades e suas respostas, dicionário ilustrado, guia de gramática, guia de aspectos culturais e guia para comunicação), não contemplaremos essas partes da obra neste trabalho, pois, conforme delimitamos em nosso objetivo, nosso estudo se restringirá ao exame da microestrutura dos verbetes ilustrados.

\subsection{Seleção do corpus}

O corpus deste estudo é composto por quatro verbetes ilustrados do dicionário bilíngue supracitado. Como critérios de seleção, consideramos apenas os verbetes ilustrados da direção inglês/português, pois pretendemos, para este trabalho, contemplar as relações entre texto escrito e imagético verbetes ilustrados do dicionário bilíngue no que se refere à decodificação. Dos 136 verbetes ilustrados dispostos na direção inglês/português, foram selecionados aqueles cujas relações entre escrita e imagem viessem a ser diferentes entre si. Uma vez que, no dicionário selecionado, muitos dos verbetes ilustrados apresentam um certo padrão das relações dos modos escrita-imagem, buscamos selecionar, para o corpus, verbetes que apresentassem diferentes tipos dessas relações. Dessa forma, analisamos os verbetes airplane, astonished, bus e zebra como exemplos dos tipos de relação entre os modos escrita e imagem que a direção inglês/português do dicionário selecionado para este trabalho abrange.

\subsection{Procedimentos de análise}

\footnotetext{
${ }^{7}$ Funcionalidade: se a obra lexicográfica apresenta função de codificar, relacionada à direção língua materna $(\mathrm{LM}) \rightarrow$ língua estrangeira (LE), ou de decodificar, relacionada à direção LE $\rightarrow$ LM.

Direcionalidade: se a obra apresenta ambas as direções (LM $\rightarrow$ LE e LE $\rightarrow$ LM), é bidirecional; caso traga apenas uma direção (LM $\rightarrow$ LE ou LE $\rightarrow$ LM), é monodirecional.

Reciprocidade: esse critério diz respeito ao público alvo para o qual a obra lexicográfica bilíngue se destina. Se o dicionário é destinado tanto para o falante da LM, quanto para o nativo da LE, tem-se um dicionário recíproco. Se o objetivo da obra é atender a apenas um dos dois públicos, trata-se de um dicionário nãorecíproco.
} 
Volume 14 - Número 2 - ago/dez de 2019

Após a seleção do corpus, analisamos cada um dos quatro verbetes, separadamente, tomando como base tanto as relações de status quanto as relações lógico-semânticas contempladas no modelo de Martinec e Salway (2005), apresentado no Quadro 1 da seção 3 deste artigo.

\section{Análise dos dados}

No verbete para a entrada airplane (Figura 1), no que se refere à relação de status entre o texto verbal escrito (o equivalente em português para a entrada em inglês) e a imagem, percebe-se que ambos são apresentados de forma igual e independente, pois a imagem e o texto escrito se relacionam por inteiro, e as informações fornecidas por cada modo semiótico podem ser compreendidas paralelamente, ou seja, o texto escrito não modifica a imagem e vice-versa. Nesse caso, se o consulente decidir buscar a tradução do vocábulo no texto verbal escrito, não necessitará da imagem para compreender o sentido da entrada, porque tanto o verbete na língua portuguesa quanto o significado da palavra é familiar aos usuários. Por outro lado, poderá escolher somente observar a imagem sem necessitar ler a parte escrita, pois a imagem imediatamente o remete ao equivalente na sua língua.

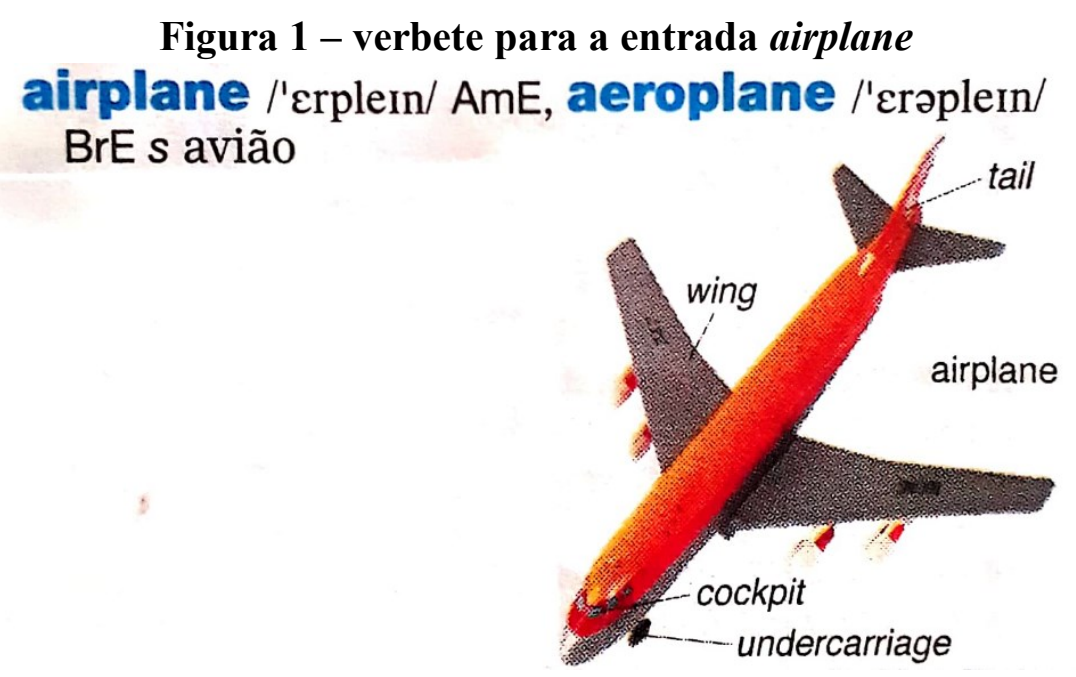

Fonte: Longman (2009, p.10).

Quanto à relação lógico-semântica, nota-se uma extensão da imagem com relação ao texto verbal escrito, pois a imagem acrescenta informações que a parte escrita não fornece, quais sejam, vocábulos em inglês designativos de algumas partes de uma aeronave (a cabine, o trem de pouso, a asa e a calda). O consulente, portanto, ao observar a imagem, terá a oportunidade de ampliar seus conhecimentos sem necessitar consultar tais vocábulos em outros verbetes do dicionário.

No verbete para a entrada astonished (Figura 2), imagem e texto escrito também se apresentam em uma relação de status do tipo igual, porém, apesar de, a princípio, escrita e imagem aparentarem estão em uma relação de independência, consideramos que ambos os modos são complementares para um entendimento efetivo por parte do consulente do verbete, pois o sentido dos equivalentes que são fornecidos (particularmente de 'estupefato', uma palavra de uso pouco frequente) poderá ser melhor compreendido pelo consulente se este observar a imagem. Da mesma forma, os equivalentes no texto verbal escrito definem de modo exato qual sentimento é expresso pela expressão do rosto da participante da imagem. No que tange à relação lógico-semântica, texto escrito e imagem encontram-se em relação de exposição, pois ambos os modos se apresentam em um mesmo nível de generalidade. 
Volume 14 - Número 2 - ago/dez de 2019

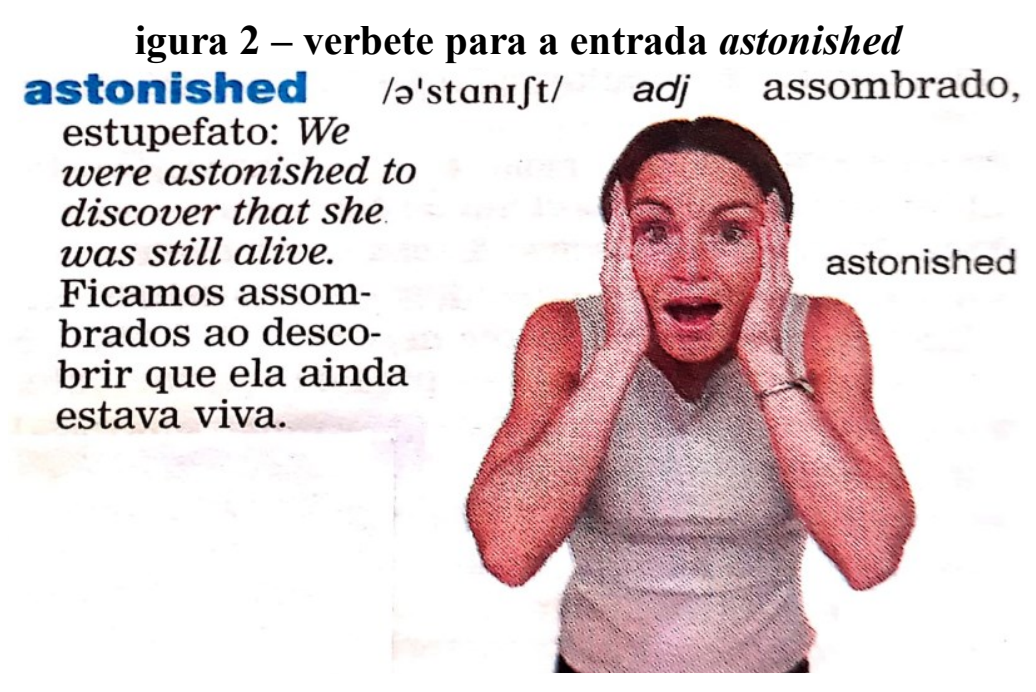

Fonte: Longman (2009, p. 24).

No verbete para a entrada bus (Figura 3), quanto à relação de status, nota-se uma igualdade entre a imagem e o texto verbal escrito da primeira acepção do verbete, acepção esta demarcada pelo numeral 1. Podemos afirmar, inclusive, que a imagem e o texto verbal escrito constituinte da primeira acepção são independentes, ou seja, sem a imagem, o texto escrito explica a si mesmo e, da mesma forma, sem a parte escrita, a imagem é autoexplicativa. No que se refere à segunda acepção do verbete, demarcada pelo numeral 2 , na qual são apresentadas expressões relacionadas com a entrada, como bus driver - motorista de ônibus - e bus fare - passagem de ônibus, podemos perceber que a relação é de desigualdade, diferente do observado na relação da imagem com o texto verbal da primeira acepção. Ao analisarmos a acepção demarcada pelo numeral 2, percebemos que o texto verbal é subordinado à imagem, visto que traz expressões bastante específicas relacionadas a esta. $\mathrm{O}$ motorista (driver) ao qual o texto verbal se refere é o do ônibus, veículo representado pela imagem. O mesmo pode ser observado para a palavra passagem (fare). Logo, devido a esse caráter de subordinação que o texto verbal escrito apresenta em relação à imagem, compreendemos, nesse caso, uma relação de status desigual.

\section{Figura 3 - verbete para a entrada bus}

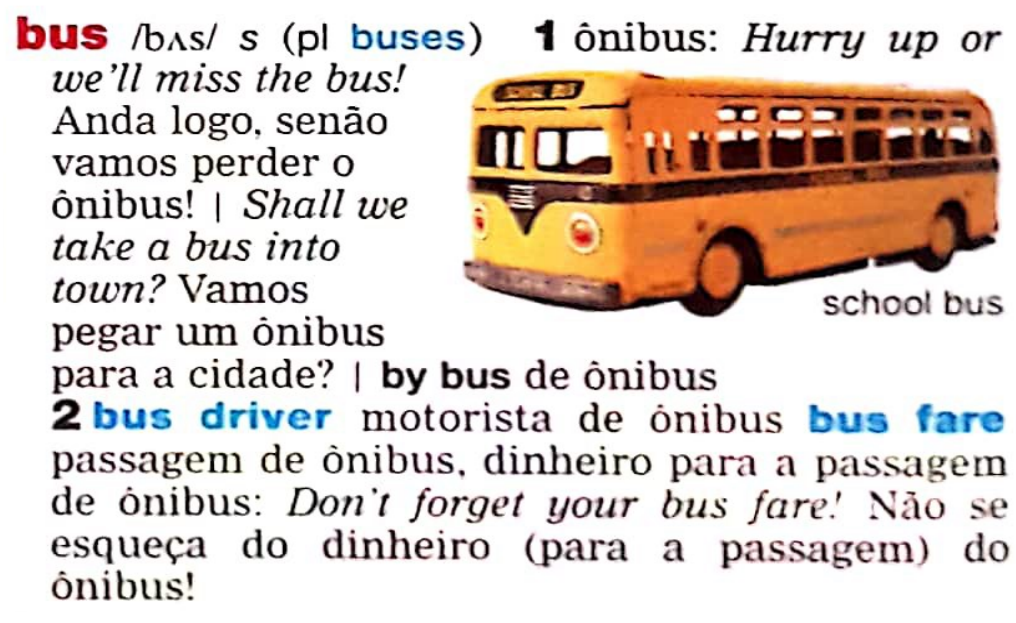

Fonte: Longman (2009, p. 52).

No que concerne à relação lógico-semântica, podemos considerar que a imagem e o texto verbal escrito da primeira acepção apresentam-se em uma relação de expansão do tipo elaboração. Como subdivisão da relação de elaboração, observamos, ainda, nesse caso, uma 
Volume 14 - Número 2 - ago/dez de 2019

exemplificação, já que a imagem representa apenas um dos tipos possíveis de ônibus existentes, pois traz a representação de um ônibus utilizado para uma função específica, ou seja, um ônibus escolar. Quanto à relação entre a imagem e a segunda acepção do verbete, nota-se que o texto verbal escrito adiciona novas informações ao verbete, sendo trazido como uma curiosidade, como algo além do significado geral do verbete. Consideramos, portanto, que essa relação lógico-semântica, que é de expansão, é, também, de extensão.

Por fim, no verbete para a entrada zebra (Figura 4), texto escrito e imagem apresentam-se em uma relação de status do tipo igual e independente, pois ambos os modos se relacionam entre si no seu todo e cada um fornece ao consulente informações suficientes para o entendimento do sentido do verbete entrada.

Figura 4 - verbete para a entrada zebra

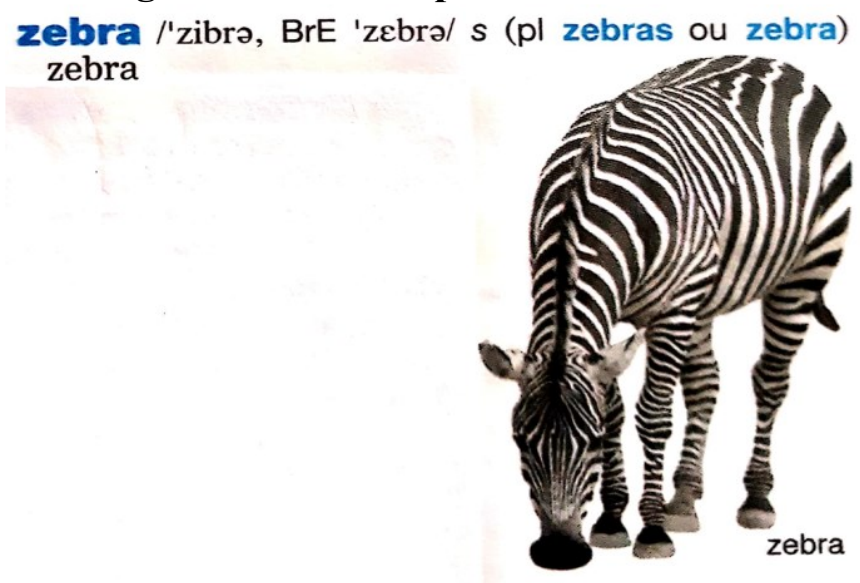

Fonte: Longman (2009, p. 421)

No que diz respeito à relação lógico-semântica, texto escrito e imagem apresentam-se em exposição, ou seja, em um mesmo nível de generalidade. Porém, outra leitura se faz possível se considerarmos o fato de o consulente, porventura, não ter um conhecimento prévio acerca das características físicas de uma zebra. Nesse caso, a imagem vem a ter, em relação ao texto verbal caráter de extensão, visto que adiciona novas informações ao leitor.

Embora o corpus tenha sido limitado a quatro verbetes de um dicionário bilíngue inglês-português, nossas análises mostraram que o modelo proposto por Martinec e Salway (2005) revela-se útil para os consulentes aprendizes perceberem as relações semânticas estabelecidas entre a integração dos dois modos semióticos texto escrito e imagético e como essa integração pode facilitar os consulentes a compreenderem os sentidos dos verbetes na língua inglesa.

\section{Considerações finais}

O dicionário como material didático para o ensino de língua materna e estrangeira têm, cada vez mais, utilizando-se de recursos semióticos visuais em sua composição, como fotografias, desenhos, figuras, diagramas, dentre outros. Tais recursos relacionam-se com o texto escrito para a produção de sentidos na obra. Por esse motivo, o texto lexicográfico configura-se como multimodal.

Neste artigo, analisamos de que forma o texto verbal escrito (mais especificamente, o equivalente) e a imagem se relacionam para auxiliar o consulente de dicionários bilíngues a construir sentidos do verbete consultado. Para tanto, observamos quatro verbetes ilustrados de um dicionário bilíngue, a saber, o Longman Dicionário Escolar para Estudantes Brasileiros Inglês-Português / Português-Inglês (2009), tomando como base, para nossas análises, as 
Volume 14 - Número 2 - ago/dez de 2019

diferentes relações de status e lógico-semânticas entre texto escrito e imagético concebidos por Martinec e Salway (2005).

A partir da análise das relações de status entre os modos escrito e a imagem constituintes dos verbetes, pudemos observar que ambos os modos semióticos podem se relacionar de forma igual, seja de maneira independente, em que cada modo fornece informações suficientes para o entendimento do sentido da entrada, seja de maneira complementar, na qual o conjunto das informações fornecidas por cada modo contribui para a construção do sentido da entrada. Texto escrito e imagético também podem se relacionar de forma desigual no interior do verbete. No caso analisado, o texto verbal escrito encontra-se em uma relação de dependência para com a imagem.

No que se refere ao exame das relações lógico-semânticas entre os dois modos semióticos, foi verificada a ocorrência de relações de elaboração do tipo exposição, em que texto escrito e imagético encontram-se em um mesmo nível de generalidade, como também relações de elaboração do tipo exemplificação, em que o texto imagético funciona como uma representação específica do texto verbal escrito, que expressa um sentido mais geral. Além dessas relações, foi verificada, também, a existência de relações de extensão, na qual a imagem acrescenta informações que não são fornecidas pelo texto verbal escrito, ou viceversa.

Conforme pudemos constatar na análise dos verbetes para as entradas astonished e $z e b r a$, relações distintas àquelas provavelmente pretendidas pelo produtor da obra podem ser estabelecidas pelo consulente dos verbetes, dependendo do conhecimento prévio que este possua ou não no que diz respeito ao item consultado. Contudo, tal fato só poderá ser comprovado através de uma investigação da leitura dos verbetes por sujeitos usuários do dicionário. É o tópico que sugerimos para um próximo estudo.

\section{Referências}

BARCELOS, V. R. O uso didático do dicionário escolar bilíngue português-inglês / inglêsportuguês na sala de aula de inglês como língua estrangeira. Percursos linguísticos, Vitória, v. 4, n. 9, p. 9-18, 2014. Disponível

em: $<$ http://periodicos.ufes.br/percursos/article/view/7437/6202> Acesso em: 29 out. 2019

BARTHES, R. Rhetoric of the image. In:__. Image, music, text. Essays selected and translated by Stephen Health. London: Fontana Press, 1977. p. 32-51.

BATEMAN, J. A. Text-image diversity: characterizing the relationships. In: image. London/New York: Routledge, 2014. p. 30-49. Text and

BRASIL. Base Nacional Comum Curricular. Brasília: Ministério da Educação, Secretaria de Educação Básica, 2017, 600 p. Disponível em:

$<\underline{\text { http://basenacionalcomum.mec.gov.br/images/BNCC_EI_EF_110518_versaofinal_site.pdf }>}$ Acesso em: 09 jan. 2020.

PNLD 2012: Dicionários . Brasília: Ministério da Educação, Secretaria de Educação Básica, 2012, 148 p. Disponível em:

$<$ http://portal.mec.gov.br/index.php?option $=$ com docman\&view $=$ download\&alias $=12059$ dicionario-em-sala-de-aula-pnld-pdf\&Itemid=30192> Acesso em: 29 out 2019.

DURAN, M. S. Dicionários bilíngues pedagógicos: análise, reflexões e propostas. 2004. 132 f. Dissertação (Mestrado em Estudos Linguísticos) - Universidade Estadual Paulista, São José do Rio Preto, 2004. Disponível em:

$<$ https://repositorio.unesp.br/bitstream/handle/11449/86601/duran_ms me sjrp_prot.pdf?sequ ence $=1 \&$ is Allowed $=\mathrm{y}>$ Acesso em: 29 out 2019.

HALLIDAY, M. A. K.; MATTHIESSEN, C. M. I. M. Halliday's introduction to functional grammar. 4. ed. London/New York: Routledge, 2014, 689 p. 
HÖFLING, C.; SILVA, M. C. P. da; TOSQUI, P. O dicionário como material didático na aula de língua estrangeira. Intercâmbio, São Paulo, v.13, p. 1-7, 2004. Disponível em:

$<$ https://revistas.pucsp.br/intercambio/article/view/3977/2625> Acesso em: 29 out 2019.

HUMBLÉ, P. Melhor do que muitos pensam. Quatro dicionários bilíngues português-inglês de uso escolar. Cadernos de tradução, Florianópolis, v. 2, n. 18, p. 253-273, 2006.

Disponível em:

$<$ https://periodicos.ufsc.br/index.php/traducao/article/view/6951/6459> Acesso em: 29 out 2019.

JEWITT, C.; OYAMA, R. Visual meaning: a social semiotic approach. In: VAN LEEUWEN, T.; JEWITT, C. Handbook of visual analysis. London: SAGE, 2008. p. 134-156.

JEWITT, C. An introduction to multimodality. In: (Ed.). The Routledge handbook of multimodal analysis. 2. ed. London/New York: Routledge, 2014, p.15-30.

KRESS, G. R.; VAN LEEUWEN, T. Reading images: the grammar of visual design. 2. ed. London/New York: Routledge, 2006, 291 p.

LEW, R. Multimodal Lexicography: the representation of meaning in electronic dictionaries.

Lexikos, v. 20, p. 290-306, 2010. Disponível

em: $<$ https://lexikos.journals.ac.za/pub/article/view/144/85 $>$ Acesso em: 29 out 2019.

LIMA, E. P. de; ARAÚJO, E. M. V. M.; PONTES, A. L. A relação texto-imagem em verbetes de um dicionário de língua inglesa. Diálogo das Letras, Pau dos Ferros, v. 5, n. 2, p. 51-67, jul./dez. 2016. Disponível

em: $<$ http://periodicos.uern.br/index.php/dialogodasletras/article/view/2135/1171 $>$ Acesso em 20 out 2019.

LONGMAN dicionário escolar inglês-português / português-inglês para estudantes brasileiros. 2. ed. Harlow: Pearson, 2009.

MARTINEC, R.; SALWAY, A. A system for image-text relations in new (and old) media. Visual communication, London, Thousand Oaks, CA and New Delhi: SAGE Publications, v. 4, n.3, p. 339-374, 2005. Disponível em:

$<$ https://journals.sagepub.com/doi/abs/10.1177/1470357205055928> Acesso em: 29 out 2019. VAN LEEUWEN, T. Introducing Social Semiotics. London/New York: Routledge, 2005, $301 \mathrm{p}$. 